\title{
FTIR imaging and ATR-FT-Far-IR synchrotron spectroscopy of pig ear skin
}

\author{
Tanja M. Greve ${ }^{\mathrm{a}, \mathrm{b}, *}$, Kristine B. Andersen ${ }^{\mathrm{a}}$, Ole F. Nielsen ${ }^{\mathrm{b}}$ and Anders Engdahl ${ }^{\mathrm{c}}$ \\ a Spectroscopy and Physical Chemistry, LEO Pharma A/S, Ballerup, Denmark \\ ${ }^{\mathrm{b}}$ Department of Chemistry, University of Copenhagen, Copenhagen, Denmark \\ ${ }^{\mathrm{c}}$ MAX-lab, Lund University, Lund, Sweden
}

\begin{abstract}
FTIR imaging was performed on pig ear skin samples cryo-sectioned perpendicular to the skin surface. The $\mathrm{OH}-$ stretch region revealed the distribution of water; the amide II band gave the protein distribution; the $\mathrm{C}=\mathrm{O}$ stretch and $\mathrm{C}-\mathrm{H}$ stretch regions showed the variation in lipids. Water and proteins were similarly distributed. Triglycerides were predominantly found in the deeper skin layers whereas free fatty acids and ceramides were more dominant in the upper layers. ATR-FT-Far-IR spectroscopy with synchrotron radiation was used on full thickness pig ear skin biopsies. The Far-IR spectra showed bands in the region from $100-150 \mathrm{~cm}^{-1}$ due to hydrogen bonded proteins and a band around $180 \mathrm{~cm}^{-1}$ arising from "free" water.

Keywords: FTIR imaging, ATR-FT-Far-IR spectroscopy, synchrotron radiation, pig ear skin
\end{abstract}

\section{Introduction}

Human skin is a complex multi-layered organ which acts as a barrier to prevent water loss and to protect the body from chemical and microbial attack. The skin essentially consists of three layers - the epidermis, dermis and the subcutaneous fatty layer. The barrier function of skin is mainly dependent on the stratum corneum (SC) which is a part of the epidermis and is the outermost layer of the skin. SC is only about 10-20 $\mu \mathrm{m}$ thick and comprises approximately 15 layers [23]. Epidermis has a thickness of 75$150 \mu \mathrm{m}$ whereas dermis is in general 1-2 mm thick [23]. Understanding the properties and characteristics of the different skin layers is of crucial importance in the dermatological research [10,12,13]. Pig ear skin is a well-accepted and readily available model for the human barrier [26]. In the present study pig ear skin was studied using FTIR imaging on cryo-sectioned skin samples. The advantage of FTIR imaging, as compared to conventional FTIR measurements, is the ability of analyzing the spatial distribution of the skin constituents.

Hydrogen bond vibrational modes give rise to bands in the Far-IR region below $400 \mathrm{~cm}^{-1}$. This region has traditionally been difficult to access. In the Far-IR region the synchrotron light source is more efficient than the conventional globar [11]. Hydrogen bond formations and breakings are important for conformational changes of skin proteins and are also important in the analysis of water which is the most abundant substance of the skin. Water/protein interactions were previously investigated by lowwavenumber Raman spectroscopy in the $\mathrm{R}(\bar{\nu})$-representation and a distinction between protein bound

\footnotetext{
*Corresponding author: Tanja M. Greve, LEO Pharma A/S, Spectroscopy and Physical Chemistry, Industriparken 55, DK-2750 Ballerup, Denmark. Tel.: +45 7226 2912; Fax: +45 7226 3321; E-mail: tanja.greve@leo-pharma.com.
} 
water and "free" water with a water structure like that in liquid bulk water was performed [10,21,22]. A water band at $180 \mathrm{~cm}^{-1}$ was assigned to the presence of water with a tetrahedral hydrogen bond conformation $[10,21,22]$. This band is significant for water with a bulk-like structure and the band was used to monitor the presence of "free" water in human skin hair and nail [6], in photo aged and chronically aged skin [7] and in malignant and benign skin tumors [8]. The water band at $180 \mathrm{~cm}^{-1}$ is not very intense in the Raman spectrum and the idea in the present project is to use Far-IR with synchrotron radiation in order to improve the detection limit for this band at very low-water concentrations in samples of biological interest.

\section{Materials and methods}

\subsection{Skin samples}

Pig ears were obtained from a local abattoir within a few hours post-mortem. The skin surface was washed and dried. The Far-IR measurements were performed on full thickness skin biopsies as approximately $3 \times 3 \mathrm{~cm}$ skin was cut off the ear and then subcutaneous fat was removed. For the imaging transmission spectra skin samples were prepared by freezing at $-80^{\circ} \mathrm{C}$ for 1 day followed by serial cryo-sectioning perpendicular to the skin surface at $5 \mu \mathrm{m}$ thickness and tissue slices were mounted on a $\mathrm{BaF}_{2}$ window.

A sample of collagen-I was obtained from SIGMA.

\subsection{FTIR imaging and ATR-FT-Far-IR spectroscopy}

A Bruker Hyperion 3000 microscope coupled to a Bruker IFS66 FT-spectrometer was used to obtain FTIR imaging and FT-Far-IR spectra.

For the FTIR imaging spectra in transmission mode a conventional globar was used as light source. The detector was a $128 \times 128$ pixels mercury cadmium telluride (MCT) focal plane array (FPA) detector with a pixel distance of $40 \mu \mathrm{m}$. As the transmission mode uses a $15 \times$ objective this gives a sample area of $340 \times 340 \mu \mathrm{m}^{2}$ for each image. Mapping was performed so that each measurement consists of $3 \times 6$ images covering an approximately $1 \times 2 \mathrm{~mm}$ area of the sample. After recording the spectra, images were performed using the integrated intensities of selected spectral areas characteristic of various skin constituents and color codes are used to determine the distribution of the examined constituent. That is, integrated intensities were calculated in the amide II region $\left(1590-1480 \mathrm{~cm}^{-1}\right)[1,27]$ to evaluate the protein distribution, in the $\mathrm{C}-\mathrm{H}$ stretch $\left(2995-2830 \mathrm{~cm}^{-1}\right)$ [1] or $\mathrm{C}=\mathrm{O}$ stretch $\left(1765-1730 \mathrm{~cm}^{-1}\right)$ [1] regions to evaluate the lipid distribution and in the $\mathrm{O}-\mathrm{H}$ stretch region $\left(3650-3000 \mathrm{~cm}^{-1}\right)[1,24]$ to evaluate the water distribution. The integrated intensities were defined as the area under the curve and above a baseline defined by drawing a straight line between the end points of the interval.

For the FT-Far-IR spectra synchrotron radiation from beamline 73 at MAX I at MAX-lab, Lund, Sweden was used as a light source. The detector was a liquid He cooled bolometer. The Hyperion 3000 microscope was used in ATR mode and ATR-spectra were performed directly on full thickness pig ear skin biopsies. The penetration depth $\left(d_{p}\right)$ of the IR radiation is given by [14]:

$$
d_{p}=\lambda /\left(2 \pi \times n_{2} \times\left(\sin ^{2} \theta_{i}-\left(n_{1} / n_{2}\right)^{2}\right)^{1 / 2}\right),
$$


where $\lambda$ is the wavelength, $\theta$ is the angle of incidence of the IR beam into the sample, $n_{1}$ is the refractive index of the sample and $n_{2}$ is the refractive index of the crystal. The microscope ATR unit with a Sicrystal used in this study has an incident angle of $45^{\circ}$ and a refractive index of 3.4 (at a wavelength of $10 \mu \mathrm{m}$ [17]. The refractive index of skin is 1.55 [25] and hence the penetration depth is $2-17 \mu \mathrm{m}$ in the spectral range $450-50 \mathrm{~cm}^{-1}$. FT-Far-IR spectra of water were recorded in transmission mode of a very thin layer of water on a polyethylene plate. The FT-Far-IR spectrum of collagen was obtained in transmission mode of $2 \mathrm{mg}$ in a polyethylene-(PET) pellet.

\section{Results}

\subsection{Imaging}

Imaging from a pig ear skin sample is shown in the upper part of Fig. 1. The top in the image corresponds to the surface of the pig ear. The numbers on the $X$ - and $Z$-axes do not refer to a distance from a specific reference point, but variations in the numbers give distances in the image. That is, the epidermis - SC inclusive - is in general found above the 31,500 mark on the $Z$-axis whereas the remainder of
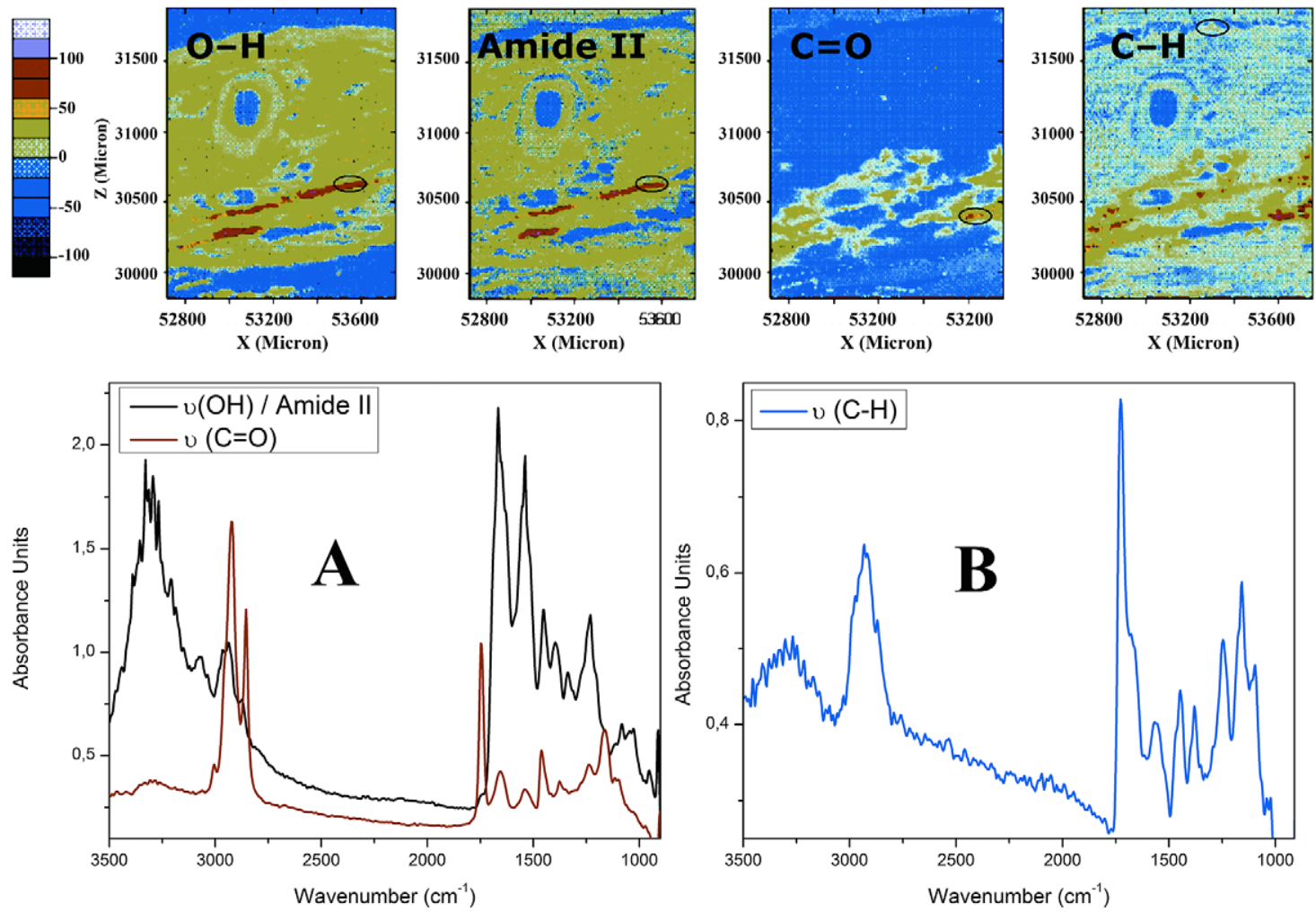

Fig. 1. FTIR images and extracted spectra from a cryo-sectioned pig ear skin sample - with skin surface at the top of the image. Top (from left to right): Integrated intensities of the water OH-stretch region $\left(3650-3000 \mathrm{~cm}^{-1}\right.$ ), of the amide II band (1590-1480 $\left.\mathrm{cm}^{-1}\right)$, of the CO stretch region $\left(1765-1735 \mathrm{~cm}^{-1}\right)$ and of the $\mathrm{CH}$ stretch region $\left(2995-2830 \mathrm{~cm}^{-1}\right)$. (A) Extracted spectra from areas in dermis with high concentrations of proteins/water (black curve) or esters (red curve). (B) Extracted spectrum from an area in epidermis. Circles in the images mark the areas from where the spectra have been extracted. (The colors are visible in the online version of the article.) 
the image is the dermis and possibly some un-removed subcutaneous fat. The images in Fig. 1 show in the top row from left to right the distribution of water $(\mathrm{O}-\mathrm{H})$, protein (amide II), triglycerides (ester $\mathrm{C}=\mathrm{O}$ ) and lipids in general (long chain $\mathrm{C}-\mathrm{H})$. The images in Fig. 1 show that water $(\mathrm{O}-\mathrm{H})$ and proteins (amide II) are very similarly distributed across the skin. In Fig. 1A is shown the extracted spectra from an area rich in proteins and water (black curve) and triglycerides (red curve). In the black curve the $3200 \mathrm{~cm}^{-1}$ band characteristic of water and the amide I and II bands (at 1650 and $1540 \mathrm{~cm}^{-1}$, respectively) characteristic of proteins are the dominating features, but the spectrum show several bands in the lower wavenumber regions as well: The $1080 \mathrm{~cm}^{-1}$ band is rather prominent in the extracted protein/water spectrum, hence showing that the origin of this band is probably protein based. This band is previously unassigned in the literature and as it plays an important role in the characterization and differentiation of human and pig ear skin [13] the assignment of the $1080 \mathrm{~cm}^{-1}$ band to proteins is a very important finding. The images further show that triglycerides $(\mathrm{C}=\mathrm{O})$ are predominantly found in the lower layers of the dermis approximately 1000-1700 $\mu \mathrm{m}$ from the skin surface - determined from the integral areas of the $1750 \mathrm{~cm}^{-1} \mathrm{C}=\mathrm{O}$ stretching band - whereas lipids in general are found in all layers - determined from the integral areas of the $\mathrm{C}-\mathrm{H}$ stretching bands. The extracted spectrum in Fig. 1B from an area rich in $\mathrm{CH}$ (but without the $1750 \mathrm{~cm}^{-1}$ band) is revealing a mixture of free fatty acids and ceramides. The presence and content of free fatty acids is determined from the $\mathrm{C}=\mathrm{O}$ band at $1725 \mathrm{~cm}^{-1}$ [31]. The presence and content of ceramides is determined from the amide I and II bands at 1675 and $1555 \mathrm{~cm}^{-1}$ and from the relationship between the amide bands and the $\mathrm{CH}$-stretching vibration bands of which the $\mathrm{CH}$ stretching vibration bands are the strongest ones in spectra of ceramides [20] and the amid bands are the strongest ones in spectra of skin proteins [1].

In previously published reports on the composition and distribution of the skin lipids the triglyceride content in epidermis ranges from $1 \%$ to $25 \%$ of the total lipid content $[5,9,15,16,18,19,28]$. However, there seems to be a tendency that in all cases where only the epidermis was removed from the skin very little triglyceride is reported $[15,16,28]$. In studies where triglycerides are included as a major constituent of epidermal lipids full thickness skin was excised before separation of the epidermis $[5,9,18,19]$. Thus, in the latter case epidermal tissue may be contaminated by subcutaneous fat as the present study confirms that triglycerides are largely absent from the epidermis. On the other hand, triglycerides are found as a major constituent of subcutaneous fat [3] in agreement with the areas found in the lower part of the image in Fig. 1 showing the $\mathrm{C}=\mathrm{O}$ distribution being either due to unremoved subcutaneous tissue or contamination of the lower layers of dermis.

The primary lipid classes in pig stratum corneum are ceramides and free fatty acids [30] agreeing with the extracted spectrum in Fig. 1B from the outermost layers of the skin showing the characteristic peaks of both ceramides and fatty acids.

\subsection{FT-Far-IR spectra}

$R(\bar{\nu})$-representations of the low-wavenumber Raman spectra from human and animal samples have previously been published [6-8,10,11,21,22]. An ATR-FT-Far-IR spectrum of pig ear is shown in Fig. 2. The Far-IR spectrum in Fig. 2 shows an intense band around $110-130 \mathrm{~cm}^{-1}$. A similar band in the lowwavenumber Raman spectra was assigned to protein hydrogen bond modes [29]. Keratins are the most abundant proteins in stratum corneum. Unfortunately no sample of keratins was available. Instead a FarIR spectrum of a similar skin protein, collagen-I, is included in Fig. 2. The band around $110-130 \mathrm{~cm}^{-1}$ is assigned to hydrogen bond modes in the proteins.

A broad band around $180 \mathrm{~cm}^{-1}$ in Fig. 2 is in analogy with Raman results in the $R(\bar{\nu})$-representation assigned to the presence of water with a tetrahedral hydrogen bond conformation significant for water 


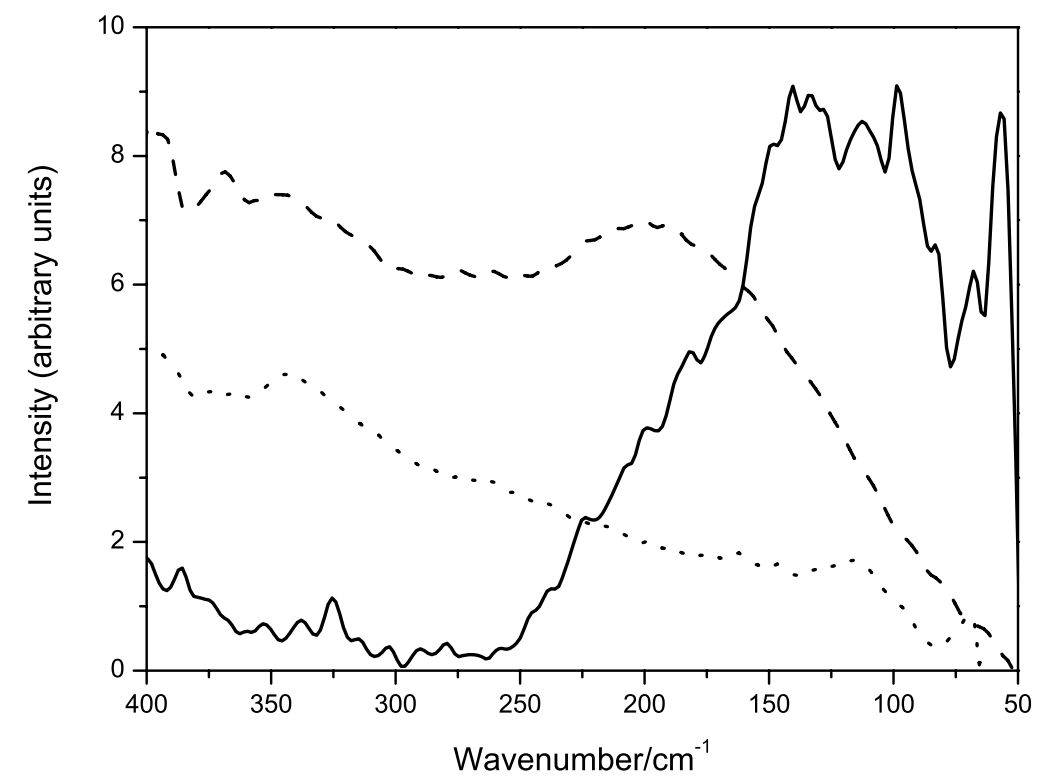

Fig. 2. ATR-FT-Far-IR spectra of pig ear skin samples (full); FT-Far-IR spectra of water (broken) and collagen-I (dotted).

with a bulk like structure; i.e. "free" water as opposed to protein-bound water $[4,10,22]$. The overall water content in the outer part of stratum corneum is only around 30\% until a depth of approximately $5 \mu \mathrm{m}$ in human forearm skin [2]. Assuming a similar water distribution for pig ear skin, the weak band around $180 \mathrm{~cm}^{-1}$ in the spectrum of pig ear (Fig. 2) can be assigned to the presence of water with a "free" bulk like structure. A Far-IR spectrum of pure water is included in Fig. 2. Due to the principles of the ATR technique, the Far-IR radiation only penetrates the stratum corneum, where the water content is low [2].

The $180 \mathrm{~cm}^{-1}$ band can in general be used to identify water with a structure like that in bulk liquid water and thus contribute to a distinction between protein bound water and "free" water. This band can be used to identify the presence of bulk liquid water in skin biopsies after freezing and thawing [10]. Skin from humans, pig ears, Guinea pigs and mice showed different water contents [10]. An estimation of the "free" water content in skin is very important for the selection of animal skin for laboratory skin penetration studies of pharmaceuticals - in particular for the mechanism of skin penetration enhancers like dimethyl sulfoxide (DMSO) [12].

\section{Conclusion}

The FTIR imaging spectra show that water and proteins are similarly distributed as free water is easily removed from the cryo-sectioned skin samples and only protein bound water remains. The images show that free fatty acids and ceramides are predominantly found in the upper layers of the skin whereas triglycerides are found in the deeper layers. Further, by extraction of single spectra from different areas of the images new correlations between the various bands from proteins became clear. Hence, the previously unassigned band at $1080 \mathrm{~cm}^{-1}$ was assigned to proteins. This is important to the research of using spectroscopy for skin characterization and investigation [13]. 
The recorded Far-IR spectra were very similar to the previously published $R(\bar{\nu})$-representation of the low-wavenumber Raman spectra from various skin samples. Thus, the result indicates that a combination of Far-IR and low-wavenumber Raman spectroscopy can be used for a better description of water/protein interactions on a molecular level in skin samples. Such a description would have a major impact on the analysis of skin properties.

\section{Acknowledgements}

A. Engdahl and O.F. Nielsen are grateful to the Wallenberg Foundation for funding of the FTIRinstrument at MAX-lab. T.M. Greve and O.F. Nielsen thank the Danish Agency for Science, Technology and Innovation for travel support through a Dansync grant and for a $\mathrm{PhD}$ grant to T.M. Greve.

\section{References}

[1] B.W. Barry, H.G.M. Edwards and A.C. Williams, Fourier transform Raman and infrared vibrational study of human skin; assignment of spectral bands, Journal of Raman Spectroscopy 23 (1992), 641-645.

[2] P.J. Caspers, G.W. Lucassen, E.A. Carter, H.A. Bruining and G.J. Puppels, In vivo confocal Raman microspectroscopy of the skin; non-invasive determination of molecular concentration profiles, Journal of Investigative Dermatology 116 (2001), 434-442.

[3] P.J. Caspers, G.W. Lucassen, R. Wolthius, H.A. Bruining and G.J. Puppels, In vitro and in vivo Raman spectroscopy of human skin, Biospectroscopy 4 (1998), 31-39.

[4] S.E.M. Colaianni and O.F. Nielsen, Low-frequency Raman spectroscopy, Journal of Molecular Structure 347 (1995), 267-284.

[5] P. Cox and C.A. Squier, Variations in lipids in different layers of porcine epidermis, Journal of Investigative Dermatology 87 (1996), 741-744.

[6] M. Gniadecka, O.F. Nielsen, D.H. Christensen and H.C. Wulf, Structure of water, proteins and lipids in intact human skin, hair and nail, Journal of Investigative Dermatology 110 (1998), 393-398.

[7] M. Gniadecka, O.F. Nielsen, S. Wessel, M. Heidenheim, D.H. Christensen and H.C. Wulf, Water and protein structure in photoaged and chronically aged skin, Journal of Investigative Dermatology 111 (1998), 1129-1132.

[8] M. Gniadecka, O.F. Nielsen and H.C. Wulf, Water content and structure in malignant and benign skin tumours, Journal of Molecular Structure 661 (2003), 405-410.

[9] G.M. Gray and H.J. Yardley, Lipid compositions of cells isolated from pig human and rat epidermis, Journal of Lipid Research 16 (1975), 434-440.

[10] T.M. Greve, N.R. Andersen, K.B. Andersen, M. Gniadecka, H.C. Wulf and O.F. Nielsen, Biomedical aspects of water structure in human and animal skin; a near-infrared Fourier transform Raman study, in: New Approaches in Biomedical Spectroscopy, K. Kneipp et al., eds, ACS Symposium Series, Vol. 963, American Chemical Society, Washington, DC, 2007, pp. 30-40.

[11] T.M. Greve, K.B. Andersen, A. Engdahl, B. Nelander and O.F. Nielsen, Hydrogen bonding in proteins and water studied by Far-IR and low-wavenumber Raman spectroscopy, AIP Conference Proceedings 1075 (2008), 13-17.

[12] T.M. Greve, K.B. Andersen and O.F. Nielsen, Spectroscopy 22 (2008), 405-417.

[13] T.M. Greve, K.B. Andersen and O.F. Nielsen, Spectroscopy 22 (2008), 437-457.

[14] N.J. Harrick, Internal Reflection Spectroscopy, Interscience, New York, 1967.

[15] C.L. Hedberg, P.W. Wertz and D.T. Downing, The nonpolar lipids of pig epidermis, Journal of Investigative Dermatology 90 (1988), 225-229.

[16] C.L. Hedberg, P.W. Wertz and D.T. Downing, The time course of lipid biosynthesis in pig epidermis, Journal of Investigative Dermatology 91 (1988), 169-174.

[17] H.W. Icenogle, B.C. Platt and W.L. Wolfe, Refractive indexes and temperature coefficients of germanium and silicon, Applied Optics 15 (1976), 2348-2351.

[18] M.A. Lampe, A.L. Burlingame, J. Whitney, M.L. Williams, B.E. Brown, E. Roitman and P.M. Elias, Human stratum corneum lipids; characterization and regional variations, Journal of Lipid Research 24 (1983), 120-130.

[19] M.A. Lampe, M.L. Williams and P.M. Elias, Human epidermal lipids; characterization and modulations during differentiation, Journal of Lipid Research 24 (1983), 131-140. 
[20] R. Mendelsohn and D.J. Moore, Infrared determination of conformational order and phase behavior in ceramides and stratum corneum models, Methods in Enzymology 312 (2000), 228-247.

[21] O.F. Nielsen, T.M. Greve, K.B. Andersen and A. Engdahl, Asian Chemistry Letters 13 (2009), 99-106.

[22] O.F. Nielsen, C. Johansson, K.L. Jacobsen, D.H. Christensen, M.R. Wiegell, T. Pedersen, M. Gniadecka, H.C. Wulf and P. Westh, Water structure and water/protein interactions in biological materials characterized by Raman spectroscopy, in: Optical Devices and Diagnostics in Materials Science, D.L. Andrews et al., eds, Proceedings of SPIE, Vol. 4098, Bellingham, WA, 2000, pp.160-168.

[23] H. Schaefer and T.E. Redelmeier, Skin Barrier - Principles of Percutaneous Absorption, Karger, New York, 1996.

[24] J.R. Scherer, M.K. Go and S. Kint, Raman spectra and structure of water in dimethyl sulfoxide, Journal of Physical Chemistry 77 (1973), 2108-2117.

[25] R.J. Scheuplein, A survey of some fundamental aspects of the absorption and reflection of light by tissue, Journal of the Society of Cosmetic Chemists 15 (1964), 111-122.

[26] N. Sekkat, Y.N. Kalia and R.H. Guy, Biophysical study of porcine ear skin in vitro and its comparison to human skin in vivo, Journal of Pharmaceutical Science 91 (2002), 2376-2381.

[27] B. Stuart, Biological Applications of Infrared Spectroscopy, Wiley, New York, 1997.

[28] D.C. Swartzendruber, D.J. Kitko, P.W. Wertz, K.C. Madison and D.T. Downing, Isolation of corneocyte envelopes from porcine epidermis, Archives of Dermatological Research 123 (1988), 1538-1541.

[29] A. Xie, A.F.G. van der Meer and R.H. Austin, Excited-state lifetimes of far-infrared collective modes in proteins, Journal of Biological Physics 28 (2002), 147-154.

[30] H.J. Yardley, Epidermal lipids, International Journal of Cosmetic Science 9 (1987), 13-19.

[31] S. Yoshida, Y. Okazaki, T. Yamashita, H. Ueda, R. Ghadimi, A. Hosono, T. Tanaka, K. Kuriki, S. Suzuki and S. Tokudome, Analysis of human oral mucosa ex vivo for fatty acid compositions using Fourier-transform infrared spectroscopy, Lipids 43 (2008), 361-372. 


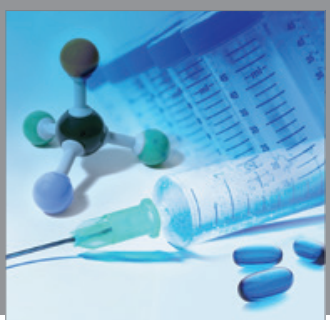

International Journal of

Medicinal Chemistry

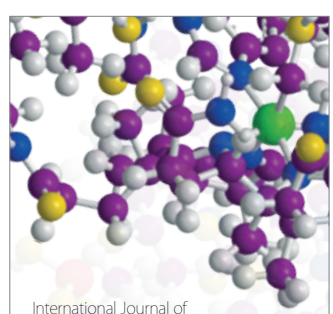

Carbohydrate Chemistry

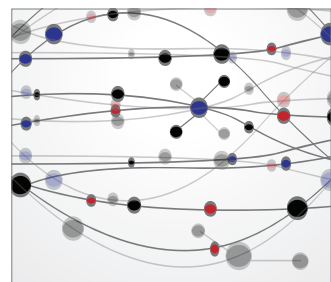

The Scientific World Journal
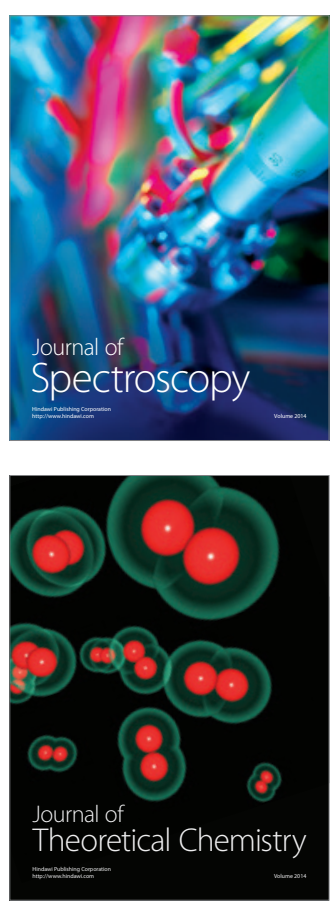
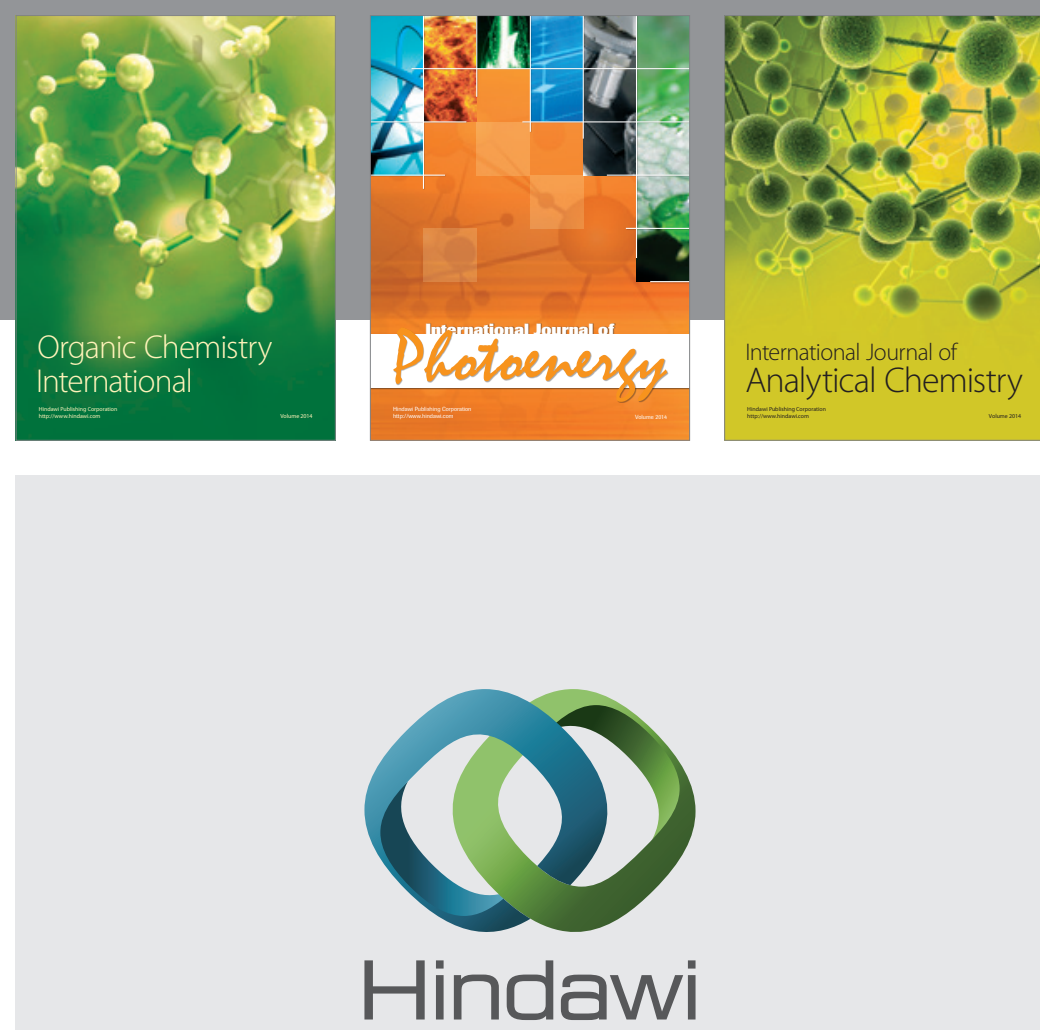

Submit your manuscripts at

http://www.hindawi.com
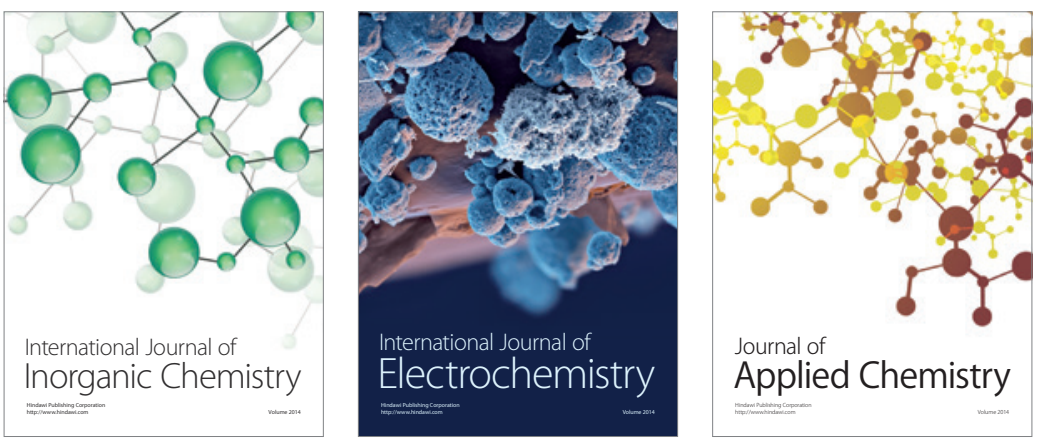

Journal of

Applied Chemistry
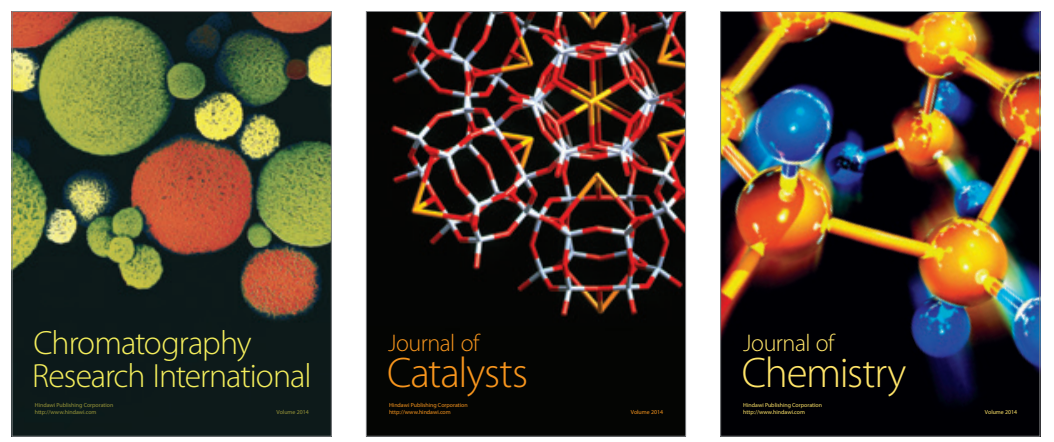
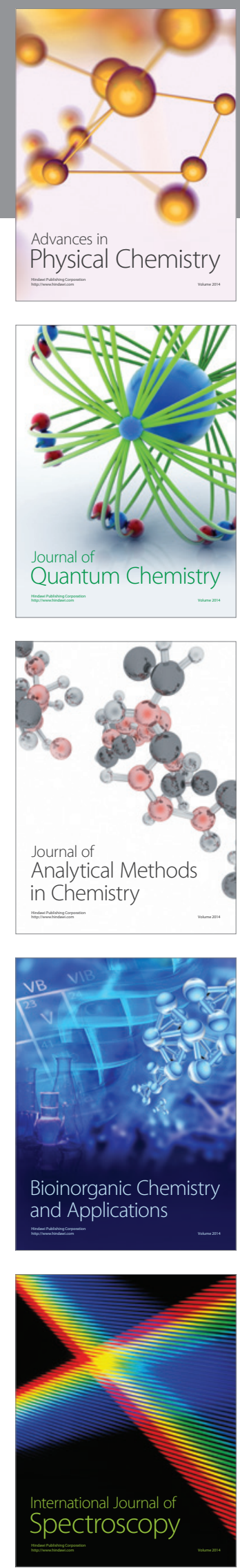